\title{
Future Historians: Their Quest for Information
}

\section{Roberto Delgadillo and Beverly P. Lynch}

This paper examines how history graduate students at one research university seek information and how they use the university library in their information-seeking process. The general question framing the study was whether graduate students in history demonstrate the same information-seeking behavior as established scholars. Related questions explored the use of new technologies and the reliance that history graduate students place on reference librarians and librarians in special collections.

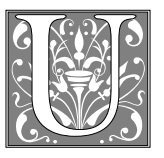

niversity librarians count historians among their most important users. Librarians have built major collections of primary source materials, including large repositories of archival and unpublished materials, in order to support the historical scholarship being carried out by the faculty and students. Long back files of journals and large monographic collections also have been acquired to support the work of historians; in these collections of secondary scholarly materials are published the results of historical research.

As library collections grow and historical scholarship expands, librarians want to know more about the kinds of materials used by historians. Librarians also seek ways to keep informed about the general areas of historical scholarship in which the local scholars are working. Although investigations of the information-seeking behavior of humanistic scholars have been growing in number and sophistication, there have been few studies of historians. Only when scholarship in history began to shift from a narrative enterprise to one using many approaches more closely related to those of the social and behavioral sciences did studies emerge that emphasized the information-seeking behavior of historians. ${ }^{1}$ Furthermore, interest continues in the materials and formats used in historical research, for it is artificial to separate the methods historians use from the materials they use. In addition to the materials historians use,

Roberto Delgadillo is a Graduate Student in Latin American Studies at UCLA; e-mail: rdelgadi@ucla.edu. Beverly P. Lynch is a Professor in the Graduate School of Education and Information Studies at UCLA; e-mail: bplynch@ucla.edu. 
however, librarians also need to know just what the historian does so as to think about and design library services that, in addition to the collections themselves, can help the historian in his or her work.

\section{Previous Investigations}

The broader study of the informationseeking behavior of humanists has provided useful information. ${ }^{2}$ These studies have helped shape this present investigation. Most of them were carried out before information technology, particularly the Internet, made its impact on libraries. Libraries had catalogs, databases, and abstracts online in the 1980s, but the explosion of the Internet and the rapid expansion of textual materials online had not yet occurred. In the previous discussions of formats and materials used by humanists, little use of online texts was reported. Humanists have used computers for word processing since the mid-1980s or so, but as has been reported by William Goodrich Jones:

Humanists [including historians] are essentially solitary workers, accustomed to spending hours with textual materials, whatever the format, and required to do so by the methodologies of the humanities. Close reading of texts and a mastery of the contents of a large number of documents are necessities. The availability of sophisticated computer technologies has not yet changed these habits of scholarship, although the technologies have changed the ways in which most scholars create the product of their research, the scholarly monograph. ${ }^{3}$

Until very recently, the principal emphasis in research libraries has been on collection development and the tools for accessing the collections. Thus it was that the early studies of historians and their use of libraries emphasized the collections and the kinds of materials historians were using. ${ }^{4}$ What was learned from these studies was that books and journals were the most frequently used materials. This was not surprising because it is in these formats that the results of historical scholarship are published. Margaret F. Stieg's work confirmed that manuscripts and materials in archival collections provide essential sources used by historians in their work. ${ }^{5}$

Walter Rundell Jr. surveyed 557 professors directing research, graduate students, librarians, and archivists; and found that the relationships between the researchers and the librarians and curators were excellent and that the historians were among the libraries' most active users. ${ }^{6} \mathrm{He}$ observed that many graduate students who were working on dissertations used collections in libraries other than their home institutions, and he discussed various protocols appropriate in using other repositories.

\section{Although humanists use many kinds of materials in their work, books and journals were used most frequently.}

Clyve Jones, Michael Chapman, and Pamela Carr Woods expanded on McAnally's citation analysis of the work of historians in U.S. history. ${ }^{7}$ From their analysis of more than seven thousand references drawn from a sample of journal articles on English history, they concluded that libraries cannot provide as much comprehensiveness in collections for historians as they can for scientists. They recommended that interlibrary lending be improved and that bibliographical control and union catalogs of holdings be expanded and updated. Their study, published in 1972, anticipated much of the development in interlibrary lending and cooperative cataloging in the United Kingdom. They concluded:

that librarians ought not to be complacent about the type of service they provide for historians. Perhaps the fact that academics often distrust the ability of librarians to provide 
the service they require is an unconscious recognition that they are not receiving the service they need from today's libraries. The way to remedy the situation is to carry out research into the needs of users, and then to apply the results to everyday practice. $^{8}$

In her 1982 review on how research libraries were meeting the needs of scholars in the humanities, Sue Stone reported that humanities scholars tended to work alone and need to browse and work with a variety of approaches to their materials. ${ }^{9}$

Although humanists use many kinds of materials in their work, books and journals were used most frequently.

Stone commented that no library could hope to provide all the materials needed by a humanistic scholar. She also noted that a number of questions relating to the work of the humanities scholar remain unanswered. The importance of browsing is often mentioned, but little is known about the nature of browsing and the outcomes of such activity. What are the relationships between research libraries and the scholar's own libraries? How do scholars use bibliographic tools and the libraries' information services?

Stephen E. Wiberley Jr. and William G. Jones studied eleven humanists, two of whom were historians. ${ }^{10}$ The results of their study showed humanists to be highly productive scholars who work alone, although four of the eleven had coauthored publications during the course of their careers. All relied partially or totally on library collections for their research, and those who used archives or other special collections reported working very closely with the archival staff. All the scholars were self-reliant at finding books and journals within the libraries they used, confirming Peter Stern's observation that the fundamentals of bibliographic research are an important part of the humanistic scholar's education and that scholars learn how to make their way to the books and journals they need..$^{11}$ The humanists rarely consulted a general ref- erence librarian but did consult regularly and freely with the archivists and curators in the special collections they were using. Wiberley and Jones concluded that humanists adopt new technologies slowly. Being more qualitative than quantitative, humanistic evidence is not as easily categorized as social science evidence is and thus is not as easily put into machine-readable form.

Marcia J. Bates, Deborah N. Wilde, and Susan Siegfried confirmed Wiberley and Jones's findings. In a study of the use of online databases by twenty-seven scholars in the humanities, the scholars said they would use online databases as supplements to their usual research methods, emphasizing that scholarly creativity requires selective and imaginative use of what is found. One scholar participating in study commented that:

... he would not recommend that students use DIALOG because he feels they should develop their research methodology manually, using their intuition, their imagination, and their ability to make associations. "I think it's very important for a student to go into a library, to be stimulated by books, and to work with books."12

Of the twenty historians studied by Donald O. Case in 1988, only three used computers to make notes and bibliographic entries. ${ }^{13}$ Most used handwritten cards or half-sheets of papers to keep track of ideas or materials important to their research and teaching.

In a later study, Case defined historians in terms of what they do and the materials they use:

Historians, then, are people who read, condense, collect, assimilate, transform, and synthesize written records of past times. They scan the environment for stimuli that match certain characteristics-a landscape that consists of texts: books, periodicals, and original source documents (such as letters, diaries, and archival 
materials) - supplemented by nontextual materials, such as pictures, photographs, and films. ${ }^{14}$

Jack King discussed the use of libraries by historians and students, providing case studies of problems historians have had in using libraries..$^{15}$ He commented that the general distrust many historians have toward librarians and the services they provide to historians will continue. He also is convinced that the reference librarians will be indispensable to the historians as electronic services continue to grow:

While historians will retain their skepticism of the reliability of library services, that skepticism will be tempered by the steadily increasing complexity of the modern library and the need for a guide, even a sometimes unreliable guide. ${ }^{16}$

Previous investigations of the work habits of established scholars have shown that humanists, including historians, work alone and that collaborative efforts are uncommon. Humanists rely on libraries and make active use of the primary and secondary sources found in them. They believe they must be self-reliant in using libraries. Both humanists and historians see the search for information as being as important as the information itself. Thus, they generally do their own literature searching. Because the humanist must interact directly and intimately with the materials, browsing in the library's collections is an important activity. Because of the nature of the library's primary collections and their organization, humanists and historians rely on curators, archivists, and special collections librarians. However, they do not rely on the general reference librarian, believing they can manage as well or better without his or her help.

Although humanists adapt to new technologies, as Wiberley and Jones concluded, they do so slowly. They have yet to confront the issues raised by digital col- lections, electronic journals, and the changing nature of research libraries within the context of a global digital society.

\section{How Do Students Work?}

All the investigations that have been carried out on the information-seeking behavior of historians have studied established historians, those who have received their Ph.D. degrees, are engaged actively in research, and are publishing the results of their historical research. Carol Collier Kuhlthau studied the library search process used by undergraduate students as they prepared research papers but did not emphasize the activities of any history students. ${ }^{17}$

\section{Both humanists and historians see the search for information as being as important as the information itself.}

The present study examines how history graduate students at one research university seek information and how they use the library in their information-seeking process. The general question framing the study was whether graduate students in history demonstrate the same information-seeking behavior as established scholars do. A related question was whether the new technologies and online services of all kinds are being used by graduate students with greater frequency than has been reported in studies of established scholars. And an important question was how much reliance history graduate students, as they pursue their studies, place on reference librarians and librarians in special collections.

\section{Methodology \\ Participants and Their Selection}

Twenty-two graduate students studying history full-time at UCLA were approached at random during the 1995 spring quarter and invited to participate in this study. Fifteen of these students agreed. 
UCLA, a Research I University in the Carnegie Classification, has a history department of more than eighty faculty. It enrolls more than three hundred graduate students and has more than a thousand undergraduate majors. The department was ranked sixth in the 1993 survey of graduate programs conducted by the National Research Council.

Study participants were assigned codes that were used throughout the interviews. These codes were assigned in order of interviews on a first-come, firstserve basis; thus, the first person interviewed is identified as P1, the second P2, and so on. Anonymity was guaranteed.

The fifteen participants were divided into three groups based on the number of years they had completed in the graduate history program. Ten of them, group A, were completing their first year's course work; three, group B, had completed three years of course work; and the remaining two participants, group C, had completed four years course work and were researching topics for their dissertations. Group A consisted of P1-P2, $\mathrm{P} 4-\mathrm{P} 5, \mathrm{P} 9-\mathrm{P} 13$, and P15; group $\mathrm{B}$ of P6-P8; and group C of P3 and P14. The participants were divided among these three groups because it was assumed that the more years they had been in formal graduate programs in history, the broader and deeper their conduct of historical scholarship. Not surprisingly, groups B and $C$ were found to be more sophisticated in conducting research than group A.

The participants consisted of twelve males and three females. Nine of the fifteen participants were born in the United States. The remaining six came from Canada, Guatemala, South Korea, the Netherlands, Mexico, and Taiwan. Eleven of the participants were native-English speakers, but all of them had an excellent command of English. Thirteen of the fifteen had received their undergraduate degrees from public universities. Fourteen expected to earn a doctorate degree in history, and one expected to earn a terminal master's degree and teach at the second- ary school level. Three were enrolled concurrently in dual-degree programs. All the participants expected to complete their degrees in approximately six to eight years. The average age was twenty-six.

\section{Content and Conduct of the Interviews}

A fourteen-item interview schedule was designed to gather information about the participants and their study of history.

The interview schedule included questions on each participant's area of concentration; whether instructors require the use of the library and its special collections; from whom he or she gets help in the library; the kinds of sources used for class assignments, term projects, and dissertations; and how these sources were found (e.g., through references in secondary sources, bibliographies, library catalogs, or from colleagues, advisers, instructors, and librarians). Use of computers was queried as was the impact of any online resources and databases. The use of other libraries and of interlibrary loan (ILL) was examined, as was how the student keeps up with trends in the field, including the journals he or she reads or scans regularly.

The interviews were conducted during the final three weeks of the 1995 spring quarter by the first-named author. They were tape-recorded and each averaged forty-five minutes in length; three interviews lasted approximately sixty minutes.

Participants were encouraged to spend as much time as possible in answering the questions. Open-ended questions and subsequent, unstructured discussions were allowed so as to probe the research questions from different vantage points. Some questions were omitted in some of the interviews. For example, it made little sense to ask participants in group A what source materials they used in determining their dissertation topics because they had not yet reached that stage of their studies.

The approach in the interviews was to allow the participants considerable freedom in responding to the questions. An open atmosphere was encouraged. Participants responded to all interview ques- 
tions unless stated otherwise. Given the use of open-ended questions and unstructured discussions, not all items in the interview schedule followed a straightforward numerical sequence. The participants were encouraged to describe their experiences from their own viewpoint and perspective.

\section{Results}

\section{Participants' Self-Perception}

All the participants defined themselves as emerging scholars engaged in the study of the written record of the past. These aspiring historians, like established historians, differ in the content and purpose of their work. Some reported being primarily interested in telling a story, others in determining and recording facts or recreating events as they actually happened, and still others in interpreting their findings in some comprehensive thesis. When asked to describe the purpose of a historian, P2 best summed up the majority of responses:

The historian must know and take into account all the existing literature on a chosen topic ... The final form of this work-a book or article-will document both the literature search and the historian's own sources and will contribute new information, new interpretations, or both, for future historians to build upon.

The research interests of the participants ranged widely. One was working in Eastern European history, one on Great Britain, three on continental Europe, two on the Far East, two on Africa, three on Latin America, and three on the United States. Current research interests included the role of the Iron Guard in modern Romanian nationalism, Spanish-Basque relations in nineteenth-century Spain, the origins of the Muslim Brotherhood in the Levant, the historical development of British journalism in nineteenth- and twentiethcentury India, political transformation in Mexico, the role of the PRI in the 1930s and 1940s, and American-Canadian diplomatic relations during the Second World War.

The participants' descriptions of their approaches to history confirmed Stieg's observation of history as being: "an umbrella covering a wide variety of specializations that have little in common with each other but their method."18 Their definitions of history provided insight to its close relations with other disciplines. In method and content, history was acknowledged as both a borrower and contributor to other fields of knowledge. This point of view was best expressed by P10: "Historians use and borrow the tools and insights by scholars in other fields to broaden their understanding of society, past and present." This was evident in the current research interests cited by those interviewed.

\section{Participants' Library Use}

Given the importance of primary and secondary material in their work, it came as no surprise that the study participants were regular users of libraries. Almost all of them (eleven of fifteen) identified UCLA's University Research Library (URL) as the library they used most often. This was expected given that the majority of resources used by the participants are located at the URL. Four participants, two from group A and one each from groups $B$ and $C$, reported also using other local public and special libraries for their work. Most of the participants (twelve of fifteen) reported using the URL and its collections on a daily basis.

In the first year of study, library use was tied closely to curriculum. Group A participants reported being required to use libraries as part of their first-year course work. Participants in groups B and C used the library unfailingly. Two participants from group A found it odd that their instructors should require them to use libraries explicitly; they felt library use to be "assumed" and "part of what it means to be a historian." By requiring their students to use libraries, instructors reinforced a work ethic that later establishes the patterns of library use by historians cited in past studies. 
When participants were asked why they went to the URL, fourteen of them reported doing so to complete class assignments. These assignments, especially for group A, were designed to give participants an orientation to the library and its resources. Other assignments called for practice in using the broad range of bibliographic tools available to historians. Typical were the following experiences:

One of my first assignments was to find the call number of a book by Mitchell A. Seligson on "aquiladoras" ... Once found, the second part of the assignment ... was finding out how many books we-the library-had on "maquiladoras" ... Next I had to use the Library of Congress Subject Headings List to look up the term "maquiladoras" ... Finally I had to search for "maquiladoras" using the command mode of the MELVYL online catalog.

My first assignment involved using Historical Abstracts (HA) to find an abstract to a 1985 article on slaves in North America ... It was a little misleading because it turned out the article abstract I sought was listed in the HA 1986 edition and not the 1985 one ... It-the experience-was useful because it really exposed me to $H A$ and made me a better researcher.

Participants cited similar experiences using America: History and Life, Reader's Guide to Periodical Literature, Dissertation Abstracts, and Book Review Index. Although all these tools were in formats other than print at the time this study was undertaken, the assignments were only to the print sources.

Fourteen of the participants also reported going to the URL to use ORION, UCLA's online information system, and MELVYL, the University of California online information system, as finding aids for materials within and outside the campus library system. Eight of fifteen par- ticipants, three from group A and all of groups B and C, identified ORION and MELVYL as essential to placing ILL requests. The use of ILL was an important part of the library experience.

When asked what areas of the library were used most often, ten participants ranked the reference collection first. Given that most of the resources (i.e., print and online bibliographic tools, atlases, etc.) needed and used by historians are kept in the reference collection, this was expected. When participants were asked if they relied on the reference staff for assistance, the overwhelming majority (thirteen of fifteen) reported doing so only when absolutely necessary, responding that the reference staff lacked the expertise needed for the level of their queries. Furthermore, most felt they had to know the library and its resources on their own terms. The two participants who reported going to the reference staff whenever possible did so because they were unfamiliar with an open stack library and were inexperienced in using a research library of the scope and size of the one at UCLA.

Four of the participants expected the reference librarians to know the library's reference collections, including new additions to it, inside out. P2 commented that:

I expect them to know their collections ... if they don't, they shouldn't be at the reference desk at all.

Heavy use was made of the Interlibrary Loan Department. Eight students (three from group A and all of groups B and $C$ ) reported using the department to drop off and inquire about ILL requests. When asked if they relied on the department staff for assistance, all eight reported doing so only when necessary. When asked why they had to use ILL, all reported doing so to obtain source materials, primary and secondary, either missing or not available at UCLA. When asked if they were satisfied with ILL, all but one reported-or rather complained-about 
the time it took to get some items to UCLA from other institutions. Overall, however, the general consensus among participants was best expressed by P14:

It's better to get something rather than nothing, or at least know where it's located ... interlibrary loan is sometimes a hit-and-miss affair, but once you know when the best times are to place requests, the rest is easy and the waiting bearable.

The third most-often-used library department was Special Collections. Students in groups $\mathrm{B}$ and $\mathrm{C}$ reported using this department, which contains rare book, manuscript, and archival collections, regularly and often. Group A participants reported using the department, but only as part of orientation assignments and not to the extent that groups $B$ and $C$ used it. When participants in groups $B$ and $C$ were asked if they relied on the special collections staff for assistance, all reported they had to depend them for their expertise in finding materials and additional sites for research. In the case of one participant, P3, special collections staff provided help in securing letters of introduction to archival institutions overseas.

Other areas of the research library used by participants in this study were microform services (three of fifteen) and the East Asian library (two of fifteen). The low use of microform services was unexpected given that historians are cited as heavy users of microforms because much of primary and secondary materials are available in no other format. ${ }^{19}$ The three participants who used microforms reported that they did not rely on the staff for assistance and, as in other studies, expressed their unhappiness with worn microform viewers and the often-grainy images of most microfilm reels. These three, unhappy as they were, reported having no choice but to make due with what was available.

The two participants who used the East Asian library reported relying on the staff for assistance. One noted:
I go to them because of their knowledge of CJK [Chinese, Japanese, and Korean] materials ... and the library's collections are greater than that of my professor's in his office. I have to learn from them as much as possible.

In addition, both participants reported being kept informed of academic and social events in their areas of study by the library's staff. A similar sense of having "to learn from them as much as possible" emerged from among three participants in group A and one in group B and some of the library's subject bibliographers. These participants were encouraged by their professors to cultivate close relationships with subject bibliographers. When asked to elaborate on their professors' rationale for such relationships, the four participants reported that it fell in line with the professors' aim of making them aware of specialists in their field who, like their professors, were familiar with the problems and techniques of conducting library research on topics in the social sciences and humanities. One of the participants noted:

In meeting with ... [Latin American Studies bibliographer], I became aware of the relative advantages and weaknesses of both the area and the subject approaches to research in Latin America.

Another reported his meetings with the African studies bibliographer as quite fruitful:

I really learned and retained a great deal of information ... I picked up on the certain distinct advantages and difficulties to a researcher in my field ... of, say, reference works versus government documents, newspapers versus various special forms ... regardless of disciplinary or theoretical orientation.

The participants identified the library's subject bibliographers as specialists who 
could step inside their areas of expertise and provide answers or information-seeking strategies to their queries.

\section{Browsing}

When not working in specific areas of the library, eleven of the fifteen participants reported that they browsed the library and its collections. Group A reported being encouraged by their professors to do so, whenever possible, to learn as much as they could about the library and its resources. Eight of group A also reported being encouraged to browse for books from different disciplines (e.g., economics, politics, and sociology) that related to the history topics they were working on. For example, two were assigned to browse for books partly or entirely on Latin America, including some very important ones for the study of Latin American history, that were found in many other sections of the collection.

Moreover, participants did not confine browsing solely to the research library stacks. Ten students reported heavy browsing of the library's periodicals room and government documents library. These participants described how they relied on the element of serendipity when browsing. Some materials they found useful were often misshelved or identified in such a way as to not reveal their exact contents. A case in point was noted by one participant who found a bibliographic source that indicated that a cache of source materials-materials he had been trying to obtain through the ILL department for the past year and a half-was in the library's storage facility, albeit microfilmed. Browsing in this manner was useful to many participants because it gave them a hands-on approach to the library and its resources.

\section{Participants' Use of Primary and Second- ary Source Materials}

The use of primary and secondary source materials is essential to the work of the history scholar. Precise definitions of primary and secondary resources are difficult to make within the context of their use by historians.
Primary source materials include diaries, letters, newspapers, magazine articles, tape recordings, pictures, and maps, contemporary to the events being investigated. Such materials may have appeared in print form before, edited or unedited, and still be a primary source. Source materials generally are considered to be secondary when the data have been distilled by other people. Secondary sources include book reviews, abstracts, journal articles, and monographs. However, such sources can become primary source documents for a historian. Thus, the same document can be a primary or a secondary source depending on the particular analysis the historian is doing. In this study, a secondary source was considered to be a monograph or a journal article, book review, or abstract. A primary source was considered to be a diary or letter in either manuscript or printed form, and newspapers, etc., contemporary to the events being studied.

When participants were asked whether they had used primary source material in completing class assignments, seven in group A reported they had. They had done so as part of exercises designed to teach how to distinguish between primary and secondary sources. Among groups $B$ and $C$, all but one participant reported using primary source material routinely in completing class assignments. When asked whether they had used secondary source material in completing class assignments, all participants reported in the affirmative.

When participants were asked how they went about seeking the materials they needed, most ranked "tracing references in secondary sources" (fifteen responses), "using bibliographies" (twelve responses), and "using library catalogs" (seven responses) as the most common ways of seeking out the materials needed to complete class assignments. Least common ways were: "talking with advisers" (four responses), "talking with colleagues" (four responses), "talking with other instructors" (two responses), and "talking with librarians" (one response). 
When asked whether they had used primary source material in completing term projects, nine out of ten in group A reported using such material. Groups B and $C$ reported relying heavily on primary source material; all five participants confirmed using it in completing term projects.

Responses by all groups as to whether they had used secondary sources again confirmed a heavy reliance on secondary source material. Responses to how participants went about in seeking out the aforementioned sources to complete term projects match very closely the earlier findings for class assignments.

\section{Participants'Use of Computers}

Computer use among participants was common. The applications used routinely were searching online catalogs and word processing. Many participants stressed the importance of ORION and MELVYL in their research, using these online information systems as "finding aids" in verifying an item's location. Most reported an initial period of difficulty in learning to use ORION and MELVYL. This usually involved having to memorize the various, but different, commands for the two systems. P10's observation was typical:

I always have to remember that I can't use ORION commands for MELVYL searches ... I still have to carry my library command handouts whenever I go to the URL.

Once learned, however, participants were quite pleased with the ORION and MELVYL search results, and considered the learning process a "rite of passage" necessary to learning to use the electronic technologies.

With respect to word processing, fourteen of the fifteen participants owned a personal computer; the student without one has free access to a twenty-four-hour computer lab near his living quarters. All reported using their computers to write and edit class assignments and term projects. Six reported using their comput- ers to compile and edit lecture notes. Typical in this respect was $\mathrm{P} 4$ 's response, who noted:

I use my computer to keep track of quotes and the author's ideas. I type in page numbers and then the quote or idea. I do this in order to outline my papers. This allows me to organize my ideas more coherently.

Despite the growing popularity and use of e-mail among the academic community, only five of the participants reported using it during the past academic year. When asked what they had used e-mail for, all five cited it as an inexpensive form of communicating with colleagues and advisers inside and outside UCLA. Those who did not use e-mail preferred to communicate with colleagues and advisers via telephone calls, scheduled visits, and notes left in the history department mailboxes. Part of the low use was the result of frustrating experiences with transmitted e-mail and hearing reports of such experiences.

In addition to online searching, word processing, and e-mail, two participants, both from group A, reported using their PCs to "shadow," and on occasion to participate in, electronic discussion groups or "lists" by and for professional scholars in the humanities and social sciences. When asked to elaborate, they reported that the lists enable them to follow current research and teaching interests, test new ideas, and share comments on current historiography. Better still, according to one participant, the lists publish book reviews, course outlines, bibliographies, listings of new sources, guides to online library catalogs and archives, and reports on new software, data sets, and CD-ROMS. Finally, one participant in group A reported using his PC to conduct statistical analyses.

\section{Participants' Awareness of Current Trends in Field of Inquiry}

Related to the question of how participants seek information is the important question of how they keep pace with trends in their field. Responses by par- 
ticipants confirm an invisible college structure. Thirteen of the fifteen participants reported being informed of the trends in history by simply talking to their respective instructor or adviser (in many instances, one and the same person). Other methods reported included attending conferences (twelve of fifteen), reading secondary source literature (eight of fifteen), and participating in courses taught by visiting scholars (three of fifteen). Although two reported watching online discussion groups, this was not seen by them as a key method in keeping up with trends in the field. One participant became aware of trends while conducting research abroad.

\section{Conclusion}

\section{Participants' Self-Perception}

Participants perceive themselves as emerging scholars in a field of inquiry that is easier to write about than define. Once defined only as the study of the past, history now encompasses the principles and findings of a diverse group of disciplines, which is clearly reflected in the participants' current research interests.

\section{Participants' Library Use}

Responses to questions of library use confirmed Rundell's observation of historians, professional and graduate alike, as being regular library users. Regular library use is essential to the work ethic of an aspiring historian, and many course assignments are designed to teach library use.

Interview responses also confirmed the importance of browsing and relying on the element of serendipity in seeking resources. Several of the participants reported that instructors assigned them the task of browsing.

Confirmed also was the tendency of historians to seek and rely on individuals they judge as being more knowledgeable than others. The library's subject bibliographers were recognized as being important specialists who could provide valuable assistance to the students as they pursued their work. Curators, archivists, and special collections librarians also were important to the student.

The reference librarians, by contrast, were perceived as generalists unable to handle the level of some history queries, even though many of the standard sources in history are located in the Reference Department.

Evidence emerged of the need and importance of ILL and the need to improve it in one area-delivery. Use of online catalogs was essential to students in their use of ILL services.

There was some confirmation of the tendency of some historians to make do with available material regardless of format.

\section{Participants' Use of Primary and Second- ary Source Material}

Responses to questions designed to measure participants' use of materials (i.e., primary versus secondary) in the preparation and completion of class assignments, term projects, and dissertation topics were consistent among the three groups of participants. The same consistency applied to questions that sought to measure how participants went about seeking source material. Overall, responses confirmed the observations of past studies that have shown historians' close relationship with primary and secondary sources. Reliance on secondary sources was heavier among group A participants than it was among the participants in groups B and C. The students in group A, in their first year of graduate study, are still learning the proverbial "lay of the land." As the students are longer in the program, they master the secondary sources and begin to work more directly with primary sources.

Responses to how participants go about seeking out source material confirms the tendency among historians to work alone and to rely heavily on secondary sources for their information seeking (i.e., bibliographies). Beginning students in group A reported relying on other students for help and on instructors and ad- 
visers for clarification in completing their work assignments. Less of this was reported among participants in groups B and $\mathrm{C}$.

\section{Participants' Use of Computers}

Responses to questions about computer use, especially e-mail use, among participants were consistent with the findings of Wiberley and Jones. In general, a positive attitude toward computers and electronic technology was expressed by all participants; but interest and applications were limited, aside from word processing and item verification via online catalogs of electronic technology. There was a growing use of computers in organizing notes and some evidence of the use of online discussions and listservs, but these uses were not commonplace.

The participants in group $\mathrm{C}$, who are at the dissertation stage, are doing what established scholars do-working alone, using primary sources for the basis of their research, and making heavy use of secondary sources. Participants in groups A and B are learning from established scholars how to identify, collect, organize, and interpret data along established lines of academic scholarship. Given the scope of what encompasses history, this process requires time and patience. Students learn the context of history, the content of history, and the processes of doing history from established scholars. The mentor-student relationship is a strong one.

However, other experts also are important to students. The students in this study were encouraged by their professors to seek help and advice from subject specialists, curators, archivists, and librarians working in special collections.

This study, conducted in the spring of 1995, reflects the emphasis on print resources. The faculty members guided the students to print resources, even though standard guides to the historical literature were available in electronic formats. The assignments did not teach the students to become aware of the new for- mats, and the attitude toward the general reference librarian contributed to the students' remaining unaware of the electronic formats. Because the students generally made their own way among the reference materials without consulting any reference librarian, the needed intervention did not occur.

In this study, the authors find that history graduate students work alone, are learning to browse, are developing the fundamentals of bibliography, are relying on library collections (local collections and others), are developing self-reliance in their discovery and use of materials, and are slowly adopting the new technologies. These behaviors are reflected in the studies of established scholars in history and the humanities.

Three questions guided this study. The first, Do graduate students in history demonstrate the same information-seeking behavior as established scholars? was answered in the affirmative. The answer to the second question, Are the new technologies and online services of all kinds used by students with greater frequency than has been reported in studies of established scholars? was less clear-cut. This may be due to the time frame of the investigation that was carried out in the spring quarter 1995 . In the time since then, there has been an extraordinary development in the Internet and the materials available online to students and scholars; and universities have been encouraging use of the Internet in all fields of study.

The third question, How much reliance do history graduate students place on reference librarians and librarians in special collections? reflected the findings in studies of established scholars. The students sought out the specialists, subject bibliographers, curators, and special collections librarians who could guide them in their specialized information needs. They did not seek out-and in many instances avoided-the general reference librarians, even though the Reference Department is where the specialized bibliographies were kept. 


\section{Discussion}

History graduate students are guided by their faculty advisors and their professors, not only within the content of the courses they take but also within the context of how they do their work. What the faculty member does is what the student does. The faculty's attitudes toward the library, collections, specialists, and generalists on the library staff become the student's attitudes.

A careful investigation of the nature and purpose of assignments to students in their first few years of graduate work would be useful in helping us to learn more about the development of the scholarly work habits of established scholars.

Browsing, identified by Stevens as an important activity more closely associated with humanists and social scientists, particularly historians, than with scientists still is an activity we know little about. Why are students assigned the activity of browsing? What is the faculty member's expectations for the student, and how are browsing outcomes identified and evaluated? Browsing within the context of these history students probably forms an important part of their relationships with their advisors, who are helping shape the way the students "see." As Jones has observed, every scholar, formative or finished, brings a theory about the world to his or her browsing and an analytical framework to the process. The activity of browsing needs a careful assessment to help understand the development of the historian's scholarly activity. Is browsing an important enough activity that libraries must design systems for it in the electronic collections?

Access to primary resource materials is essential to the work of the historian. How such materials are described, accessed, and made available as they move into digital formats will directly influence the historians' work. Bates summarized her work on the terminology of humanities scholars by noting that information seeking in the humanities has unique features that have been overlooked, result- ing in certain groups of library patrons being underserved. Are historians among these underserved? And will emerging historians be more or less underserved than established scholars?

\section{History scholars and emerging scholars, for better or worse, will continue to rely on ILL departments to get the materials they need.}

The attitudes of these graduate history students toward the general reference librarian need greater attention. These students perceived the generalists as being unable to handle the level of their history queries. Kuhlthau asserted that librarians have developed successfully good services in organizing the collections, providing ready reference for factual information needs, and negotiating with the student the kinds of information resources the information need requires. She incorporated these services in her "Zones of Intervention" and related them to the student's information search process. But the history graduate students do not visit with the general reference librarian. They are confident they can manage on their own or with the help and assistance of a specialist. Moreover, they are advised by their professors to seek out the specialists. As the experiences of subject bibliographers and some participants demonstrated, it is possible to establish meaningful and beneficial ties of communication between students and specialists in the library. As research libraries continue to reduce the number of subject bibliographers and replace professionals at reference desks with paraprofessionals and student help, what will this mean for the development of scholarly work habits of historians?

Although it is true that advances in history via electronic technology have given the student historian potential advantages undreamed of before, the historians' methods of work will change slowly, as other investigations have shown. This is explained by the need of future historians to rely on the methods of quality con- 
trol taught by an established historian who in the past did not have to rely on sophisticated systems of information. As one participant observed: "Why spent time getting lost in the vast literature of history via a computer when I know I can trust a citation noted by a historian whose work I have examined."

Students and scholars working in some areas of history, however, are likely to begin to change their work and library habits. For example, students of modern cultural history will differ from their older counterparts in their ability to find information through the World Wide Web and the internet. In the end, however, they will still have to adhere to principles of interpretation and creativity that remain unchanged by the effect of electronic technology. What elements of quality control will be developed out of work with these new resources?
With respect to ILL and access to other collections, the major issue remaining unchanged by electronic technology is that of delivery. History scholars and emerging scholars, for better or worse, will continue to rely on ILL departments to get the materials they need.

What they will assume is that a library or archive somewhere will have the resource they are seeking. Whether that will be so, as libraries continue to see erosion in materials budgets, regardless of format, remains to be seen.

As we learn more about how future historians do their work, there will be major implications for academic and research libraries. How libraries will respond and whether they will remain central to the scholarly life of the historian, one of their most important patrons, remain central questions.

\section{Notes}

1. Donald O. Case, "Collection and Use of Information by Some American Historians: A Study of Motives and Methods," Library Quarterly 61 (Jan. 1991): 1-82; __, "Conceptual Organization and Retrieval of Text by Historians: The Role of Memory and Metaphor," Journal of the American Society for Information Science 42 (Oct. 1991): 657-68; Margaret F. Stieg, "The Information Needs of Historians," College E Research Libraries 42 (Nov. 1981): 549-69; Deborah Lines Andersen, "Academic Historians, Electronic Information Access Technologies, and the World Wide Web: A Longitudinal Study of Factors Affecting Use and Barriers to That Use," Journal of the Association of History and Computing 1, no. 1 (June 1998), also available at: $h$ ttp://mcel.pacificu.edu/history/jahcI1/Anderson/Anderson.html. Deborah Lines Andersen's work was brought to the authors' attention after this paper had been completed. It concentrates on the use and nonuse made of historians of electronic information access technologies.

2. Marcia J. Bates, Deborah N. Wilde, and Susan Siegfried, "Research Practices of Humanities Scholars in an Online Environment: The Getty Online Searching Project Report No. 3," Library and Information Science Research 17 (winter 1995): 5-40; ___ "An Analysis of Search Terminology Used by Humanities Scholars: The Getty Online Searching Project Report Number 1," Library Quarterly 63 (Jan. 1993): 1-39; Elaine Broadbent, "A Study of Humanities Faculty Library Information Seeking Behavior," Cataloging \& Classification Quarterly 6 (spring 1986): 23-36; Susan S. Guest, "The Use of Bibliographical Tools by Humanities Faculty at the State University of New York at Albany," Reference Librarian 18 (summer 1987): 157-72; Humanists at Work: Disciplinary Perspectives and Personal Reflections. The Proceedings of a Symposium Held at the University of Illinois at Chicago April 27-18, 1989 (Chicago: Univ. of Illinois, 1989); Anita Lowry and Junko Stuveras, Scholarship in the Electronic Age: A Selected Bibliography on Research and Communication in the Humanities and Social Sciences (Washington, D.C.: Council on Library Resources, 1987); Rolland Stevens, "The Study of the Research Use of Libraries," Library Quarterly 26 (Jan. 1956): 41-51; Sue Stone, "Humanities Scholars: Information Needs and Uses," Journal of Documentation 38 (Dec. 1982): 292-312; Stephen E. Wiberley Jr., "Habits of Humanists: Scholarly Behavior and New Information Technologies," Library Hi Tech 9 (1991): 17-21;

Stephen E. Wiberley Jr. and William G. Jones, "Humanists Revisited: A Longitudinal Look at the Adoption of Information Technology," College \& Research Libraries 55 (Nov. 1994): 499-509; _—, "Patterns of Information Seeking in the Humanities," College \& Research Libraries 50 (Nov. 1989): $638-45$. 
3. William Goodrich Jones, "The Disappearance of the Library: Issues in the Adoption of Information Technology by Humanists," in Information Technology and the Remaking of the University Library (San Francisco: Jossey-Bass, 1995), 34.

4. Arthur M. McAnally, Characteristics of Materials Used in Research in United States History" (Ph.D. diss., University of Chicago, 1951); Clyve Jones, Michael Chapman, and Pamela Carr Woods, "The Characteristics of the Literature Used by Historians," Journal of Librarianship 4 (July 1972): 137-56.

5. Stieg, "The Information Needs of Historians," 551.

6. Walter Rundell Jr., "Relations between Historical Researchers and Custodians of Source Material," College \& Research Libraries (Nov. 1968): 466-76.

7. Jones, Chapman, and Woods, "The Characteristics of the Literature Used by Historians," $137-56$.

8. Ibid., 155.

9. Stone, "Humanities Scholars," 292-312.

10. Wiberley and Jones, "Humanists Revisited," 499-509.

11. Peter Stern, "Online in the Humanities: Problems and Possibilities," Journal of Academic Librarianship 14 (July 1988):161.

12. Bates, Wilde, and Siegfried, "Research Practices of Humanities Scholars in an Online Environment," 31-32.

13. Case, "Conceptual Organization and Retrieval of Text by Historians," 657-68.

14. - "Collection and Use of Information by Some American Historians," 63.

15. Jack King, "History Research into the 21st Century," Reference Librarian 47 (1994): 89-108.

16. Ibid., 104.

17. Carol Collier Kuhlthau, "Students and the Information Search Process: Zones of Intervention for Librarians," Advances in Librarianship 18 (1994): 57-72.

18. Stieg, "The Information Needs of Historians," 550.

19. Nena Couch and Nancy Allen, The Humanities and the Library, 2d ed. (Chicago: ALA, 1993), 75. 